\title{
Efficacy of Difenoconazole Emulsifiable Concentrate with Ionic Liquids against Cucumbers Powdery Mildew
}

\author{
Qingrong Peng, Fengmao Liu, and Chunrong Zhang \\ College of Science, China Agricultural University, Beijing 100093, China \\ Correspondence should be addressed to Qingrong Peng; qrpeng@cau.edu.cn
}

Received 5 May 2017; Revised 18 July 2017; Accepted 31 July 2017; Published 29 August 2017

Academic Editor: Swapnil A. Dharaskar

Copyright (C) 2017 Qingrong Peng et al. This is an open access article distributed under the Creative Commons Attribution License, which permits unrestricted use, distribution, and reproduction in any medium, provided the original work is properly cited.

\begin{abstract}
Among eight ionic liquids (ILs) examined, 1-n-butyl-4-methyl-pyridinium bromide (BMPyBr, 5) was used in this study as an appropriate alternative to benzene homologs and derivatives to be used in $10 \mathrm{wt} \%$ water-insoluble difenoconazole emulsifiable concentrate (EC). Moreover, $10 \mathrm{wt} \%$ difenoconazole EC with BMPyBr (5) exhibited the same efficacy as $10 \mathrm{wt} \%$ difenoconazole wettable powder (WP) against powdery mildew on cucumbers under field conditions. The results revealed that difenoconazole EC with $\mathrm{BMPyBr}(5)$ had excellent stability at $268 \mathrm{~K}$ and $327 \mathrm{~K}$ after 14 days through high-performance liquid chromatography (HPLC). Therefore, ILs can be considered as promising environment-friendly adjuvants for pesticides that are commercially processed as EC formulation.
\end{abstract}

\section{Introduction}

Powdery mildew diseases include some of the most serious plant diseases caused by plant pathogenic fungi, affecting nearly 10,000 species of angiosperms [1]. Powdery mildew disease $[2,3]$ commonly affects cucumber and other cucurbits. Powdery mildew can severely reduce yield open fields and protect cultivation $[4,5]$. Although powdery mildew is nondestructive to fruit, this disease can significantly reduce the quality and quantity of crop yields due to direct impact on leaves. Therefore, fungicides are needed to control this disease.

Difenoconazole is a broad-spectrum triazole fungicide [6]. As a systemic sterol demethylation inhibitor, difenoconazole is highly effective against the diseases caused by various fungi infecting cereals targeting ergosterol biosynthesis by inhibiting the fungal enzyme sterol-1-4-a-demethylase [79]. Given its capability to control various fungal diseases, difenoconazole has been extensively used in a wide range of crops in many countries.

A great amount of aromatic compounds are typically added to preparations of water-insoluble pesticides emulsifiable concentrate (EC). Aromatic compounds are toxic to the environment. Developed countries have completely or partially prohibited the use of toxic aromatic compounds in fruit and vegetable pesticides [10]. Research on decreasing or replacing toxic solvents is extremely important to reduce risk.

New green or environment-friendly solvents have been developed. Ionic liquids (ILs) have been accepted as a new green chemical solvent that remains in liquid form at approximately room temperature; however, these solvents are considered as a distinct set of salts composed of organic cations and inorganic anions [11-13]. Therefore, ILs are promising unconventional and environment-friendly solvents because of their unique properties, such as lack of measurable vapor pressure, high thermal stability, air and moisture stability, nonpolluting nature, low melting point (up to $-363 \mathrm{~K}$ ), retention of liquid state over a wide temperature range, good electrical conductivity, and recyclability. ILs may be used to create "designer liquids" because their physicochemical properties can be modified by the selected cations, anions, and substituents. Thus, the potential application of ILs as solvents has broadened [14]. ILs are known as liquid zeolite and exhibit the characteristics of both solids and liquids. Thus, ILs have good potential to effectively replace conventional harmful and hazardous organic solvents. ILs have recently attracted considerable interest for their possible applications in chemical synthesis $[15,16]$, electrochemistry 
[17], biocatalytic transformations [18], and analytical and separation sciences $[19,20]$. However, few studies have focused on pesticide formulation.

Although ILs can lessen the risk of air pollution because of their insignificant vapor pressure, the properties that make them the target of industrial interest (i.e., high thermal stability and nonvolatility) suggest potential problems with degradation or persistence in the environment. Zhao et al. [21] reported that an inverse relationship exists between the relative number of oxygen atoms and toxicity. However, the toxicity of ILs does not always increase with the growth of alkyl side chains. Other scientists have suggested the use of a natural product, such as amino acid, would expand the application of ILs.

In this work, we report on the preparation of difenoconazole EC with ILs instead of toxic aromatic compounds and, moreover, the primary application of ILs with the use of commercial IL diluents as solvents for agricultural pesticides. We demonstrate the efficacy of difenoconazole EC with ILs against powdery mildew on cucumbers under field conditions. These experiments were conducted four times. The results show that 1 - $n$-butyl-4-methyl-pyridinium bromide (5) is the ideal adjuvant to difenoconazole EC. Further study will be reported about the degradation of related ILs.

\section{Materials and Methods}

Eight ILs, namely, $N$-butyl-methylpyrrolidinium bromide (1), N-butyl-3-methyl-pyridinium bromide (2), $N$-butylpyridinium chloride (3), $N$-butyl- pyridinium bromide (4), N-butyl-4-methylpyridinium bromide (5), $N$-butyl-3methylimidazolium chloride (6), N-butyl-3-methylimidazolium tetrafluoroborate (7), and N-butyl-3-methylimidazolium trifluorosulfonate (8), were purchased from Shanghai Chenjie Chemical Co. Ltd. without further purification (purity $>$ 99\%). Difenoconazole was purchased from Shanghai Qinlong Chemical Co. Ltd. (purity > 97\%), and 10\% difenoconazole wettable powder (WP) was purchased from Swiss Syngenta Crop Science Co., Ltd.

2.1. Preparation of $10 w t \%$ Difenoconazole EC with ILs. A mixture of $30 \mathrm{wt} \% \mathrm{IL}, 20 \mathrm{wt} \%$ isobutanol, and $40 \mathrm{wt} \%$ water was ultrasonicated for $10 \mathrm{~min}$ in a $20 \mathrm{~mL}$ test tube. Once the solution was uniform and transparent, difenoconazole was added gradually up to $10 \mathrm{wt} \%$. The mixture was subjected to further ultrasonication for $30 \mathrm{~min}$ and then stored for two months.

2.2. High-Performance Liquid Chromatography (HPLC) Conditions. HPLC was performed using an Agilent 1100 series liquid chromatography system (Agilent Technologies, USA) with a UVD detector. A wavelength UV-vis detector and a reverse-phase C-18 column $(150 \mathrm{~mm} \times 4.6 \mathrm{~mm} \times 5 \mu \mathrm{m})$ were used at a flow rate of $1.0 \mathrm{~mL} \cdot \mathrm{min}^{-1}$. A mobile phase of methanol and water $(\mathrm{v} / \mathrm{v}=95: 5$ for difenoconazole) was used for the isocratic elution condition. The injection volume was $20 \mu \mathrm{L}$, and the detection wavelength for difenoconazole was $240 \mathrm{~nm}$.
2.3. Measurements of Physical Properties. The prepared solutions of $10 \mathrm{wt} \%$ difenoconazole EC with ILs were sealed in ampoule bottles. The bottles were stored in an incubator at $268 \mathrm{~K}$ and $327 \mathrm{~K}$ for $14 \mathrm{~d}$ to investigate the stabilities during cold and hot storage. The difenoconazole content of EC formulation was measured after $14 \mathrm{~d}$ using HPLC.

2.4. Greenhouse Trials. Greenhouse trials (area of $8 \mathrm{~m}^{2}$ ) were conducted in a plant protection test base of the Chinese Academy of Agricultural Sciences Institute located in the Changping District North Zhuang Hu. The trials were completed in a cucumber greenhouse in Beijing City. The cucumbers were primarily infected by powdery mildew caused by Podosphaera xanthii (Schlechtend.: Fr.) Pollacci. Table 1 presents the dilution rate of difenoconazole EC with ILs and commercial difenoconazole WP. Disease control was tested following the guidelines for the field efficacy trial of fungicides against powdery mildew on cucumbers $(\mathrm{GB} / \mathrm{T}$ 17980.30-2000). All trials were completed in a greenhouse. Cucumber seeds (Zhongnong number 26) were sown at $40 \mathrm{~cm}$ intervals, $70 \mathrm{~cm}$ row space. It was planted in September 27, 2013. Cucumber was trellised while it was growing. Powdery mildew on cucumber were naturally infected. Four treatment rates, namely, low, middle, and high concentrations of $10 \%$ difenoconazole EC with ILs (5) and commercial $10 \%$ difenoconazole WP, were established. An untreated sample using solvent blank except difenoconazole was the control (Table 1). The four rates were subjected to a randomized complete block design. The applications were made from $11 / 2 / 2013$ to $11 / 23 / 2013$ four times according to local practice. The application interval was one week, depending on the disease development in the field. The first application was made before or upon the appearance of the initial symptoms of powdery mildew. The experiments were arranged in a completely randomized design with four replicates.

The difenoconazole formulations were sprayed with a knapsack sprayer (DFH-16A; pore size, $1.3 \mathrm{~mm}$; spraying pressure, $0.2 \mathrm{MPa}$ to $0.4 \mathrm{MPa}$ ). Disease severities were evaluated from all the leaves for each of the 2 middle plants selected. Before application, the disease severities were investigated for all the plots. Disease severity was recorded $7 \mathrm{~d}$ after the last application with the following scale: $0=$ no symptoms, $1=0 \%$ to $5 \%, 3=6 \%$ to $10 \%, 5=11 \%$ to $20 \%, 7=21 \%$ to $40 \%$, and $9=$ more than $40 \%$ of the leaf surface covered with mildew. The disease index for each treatment was calculated using the following formula $[3,22,23]$ :

$$
\mathrm{DI}=\frac{\left(\sum_{i=0}^{9} N_{i} \times i\right)}{\sum_{i=0}^{9} N_{i} \times 9} \times 100,
$$

where $i$ is the disease severity ( 0 to 9 ) and $N_{i}$ indicates the number of leaves with the severity of $i$.

Disease control was calculated as follows [3, 22, 23]:

$$
\mathrm{DC}(\%)=\left(\frac{\mathrm{DI}_{\mathrm{UTC} 0}-\mathrm{DI}_{\mathrm{CT} 1}}{\mathrm{DI}_{\mathrm{UTC}}}\right) \times 100,
$$

where UTC0 indicates the disease severity of the untreated control before the first treatment and CT1 stands for the disease severity of any treatment after the last treatment. 
TABLE 1: Difenoconazole EC with ILs and commercial difenoconazole (WP) used for the field trials.

\begin{tabular}{|c|c|c|c|}
\hline Treatment number & Treatment & Dilute rate $\left(\mathrm{g} \cdot \mathrm{acre}^{-1}\right)$ & Active ingredients $\left(\mathrm{g} \cdot \mathrm{acre}^{-1}\right)$ \\
\hline 1 & 10 wt $\%$ difenoconazole-EC with ILs & 50.0 & 5.00 \\
\hline 2 & $10 \mathrm{wt} \%$ difenoconazole-EC with ILs & 66.7 & 6.67 \\
\hline 3 & $10 \mathrm{wt} \%$ difenoconazole-EC with ILs & 83.3 & 8.33 \\
\hline 4 & $10 \mathrm{wt} \%$ difenoconazole-WP & 66.7 & 6.67 \\
\hline 5 & Mixture of IL, isobutanol, and water & - & - \\
\hline
\end{tabular}

TABLE 2: Mutual solubility of difenoconazole, ILs, and organic cosolvents.

\begin{tabular}{lcccccccc}
\hline IL & $\mathbf{1}$ & $\mathbf{2}$ & $\mathbf{3}$ & $\mathbf{4}$ & $\mathbf{5}$ & $\mathbf{6}$ & $\mathbf{7}$ \\
\hline Organic solvent & & & & & & & \\
$\quad$ Ethanol & $\times$ & $\sqrt{ }$ & $\sqrt{ }$ & $\times$ & $\sqrt{ }$ & $\times$ & $\times$ \\
Acetone & $\times$ & $\times$ & $\times$ & $\times$ & $\times$ & $\times$ & $\times$ \\
Isobutanol & $\times$ & $\sqrt{ }$ & $\sqrt{ }$ & $\times$ & $\sqrt{ }$ & $\times$ & $\times$ \\
Isopropanol & $\times$ & $\times$ & $\times$ & $\times$ & $\times$ & $\times$ \\
\hline
\end{tabular}

Note. $\sqrt{ }$ indicates clear and transparent mixture; $\times$, suspended emulsion mixture.

\section{Results and Discussion}

3.1. Selection of ILs and Organic Cosolvents. Eight ILs and organic solvents (including ethanol, acetone, isobutanol, and isopropanol) were selected as adjuvants and cosolvents, respectively. A mixture (30 wt $\%$ IL, $40 \mathrm{wt} \%$ water, and $20 \mathrm{wt} \%$ organic solvent) was added with $0.050 \mathrm{~g}$ of difenoconazole following the experimental methods described in Materials and Methods to observe the level of transparency of the mixture. Table 2 showed the results of the experiment.

A clear and transparent mixture could not be obtained in $0.05 \mathrm{~g}$ of difenoconazole with ILs, $\underline{\mathbf{1}}, \underline{\mathbf{4}}, \underline{\mathbf{6}}, \underline{\mathbf{7}}$, and $\underline{\mathbf{8}}$ as adjuvants regardless of which organic solvent was used as cosolvent. However, a clear and transparent mixture could be obtained in difenoconazole with ILs $\underline{\mathbf{2}}, \underline{\mathbf{3}}$, and $\mathbf{5}$ and organic solvent containing ethanol or isobutanol. Further study revealed that the mixture of difenoconazole, IL $\underline{2}$ or $\underline{3}$, and organic solvent containing ethanol or isobutanol is less stable than the mixture of difenoconazole, IL 5, and organic solvent containing ethanol or isobutanol. In addition, the mixture of difenoconazole, IL $\mathbf{5}$, and isobutanol is more stable than the mixture of difenoconazole, IL 5 , and ethanol during the storage. These results confirmed that among the eight ILs, IL $\mathbf{5}$ is the most easily miscible with difenoconazole, water, and isobutanol; that is, ILs $\mathbf{5}$ was the most suitable cosolvent.

IL 5 with the $\mathrm{Br}^{-}$was presented to be more "surface active" because of the larger ionic radius when ILs were of the same cation but different counteranion head group (namely, $\mathrm{Cl}^{-}$and $\mathrm{Br}^{-}$) $[24,25]$. However, an increased "surface active" ILs with longer alkyl chain was observed when ILs have the same anion but different lengths of alkyl chain. The results show that difenoconazole EC with IL $\mathbf{5}$ is more stable. The related study explaining why IL $\mathbf{5}$ is more stable will be further reported.

Furthermore, the highest concentration of difenoconazole in EC formulation was $12 \mathrm{wt} \%$. Although the values of difenoconazole were lower than those of the commercial difenoconazole ECs, toxic organic solvent was decreased.
On the other hand, isobutanol is highly flammable, but the amount of isobutanol EC with IL $\mathbf{5}$ was $25 \mathrm{wt} \%$, which was much lower than that of toxic aromatic compounds of commercial difenoconazole ECs. Therefore, environmentfriendly difenoconazole EC with ILs $\mathbf{5}$ was prepared.

3.2. Physical Properties of $10 w t \%$ Difenoconazole EC with IL 5. The mixture of $10 \mathrm{wt} \%$ difenoconazole EC with IL 5 was stored for $14 \mathrm{~d}$ at 268 and $327 \mathrm{~K}$. The results of HPLC indicated that the decomposition of difenoconazole was $1.32 \mathrm{wt} \%$ at $268 \mathrm{~K}$ and $1.56 \mathrm{wt} \%$ at $327 \mathrm{~K}$ after $14 \mathrm{~d}$. Moreover, the decomposition of difenoconazole was $1.01 \mathrm{wt} \%$ at atmospheric temperature for two months. In all cases, the decomposition of difenoconazole was less than $5 \mathrm{wt} \%$, which is reasonable in pesticide formulation. Difenoconazole EC with IL 5 will not decompose for two years. Thus, $10 \mathrm{wt} \%$ difenoconazole EC with IL 5 was obtained, which revealed outstanding stability as an environment-friendly EC formulation.

3.3. Efficacy of the Field Trial. Table 3 shows the dilution rates of $10 \mathrm{wt} \%$ difenoconazole EC with ILs (i.e., 50.0, 66.7, and $\left.83.3 \mathrm{~g} \cdot \mathrm{acre}^{-1}\right)$. The average disease indexes were $7.5 \mathrm{c}, 5.0 \mathrm{~b}$, and $3.4 \mathrm{a}$, and the average disease controls were $86.4 \%, 90.9 \%$, and $93.8 \%$, respectively. Each mean value followed by the same letter indicates nonsignificant difference at $p=0.05$ based on Duncan's test.

These results clearly confirmed that $10 \mathrm{wt} \%$ difenoconazole EC with IL 5 provided the effective control of powdery mildew on cucumbers in the field trials. Moreover, $10 \mathrm{wt} \%$ difenoconazole EC with IL $\mathbf{5}$ was well dispersed in water. The dilute dilution rate of $10 \mathrm{wt} \%$ difenoconazole WP was $66.7 \mathrm{~g} \cdot \mathrm{acre}^{-1}$. The average disease index was $5.0 \mathrm{~b}$, and average disease control was $91.1 \%$. These results were almost equal to that of the $10 \mathrm{wt} \%$ difenoconazole EC with ILs at a dilution rate of $66.7 \mathrm{~g} \cdot \mathrm{acre}^{-1}$.

Table 3 shows that $10 \mathrm{wt} \%$ difenoconazole EC with ILs at a dilution rate of $83.3 \mathrm{~g} \cdot \mathrm{acre}^{-1}$ is most effective against 


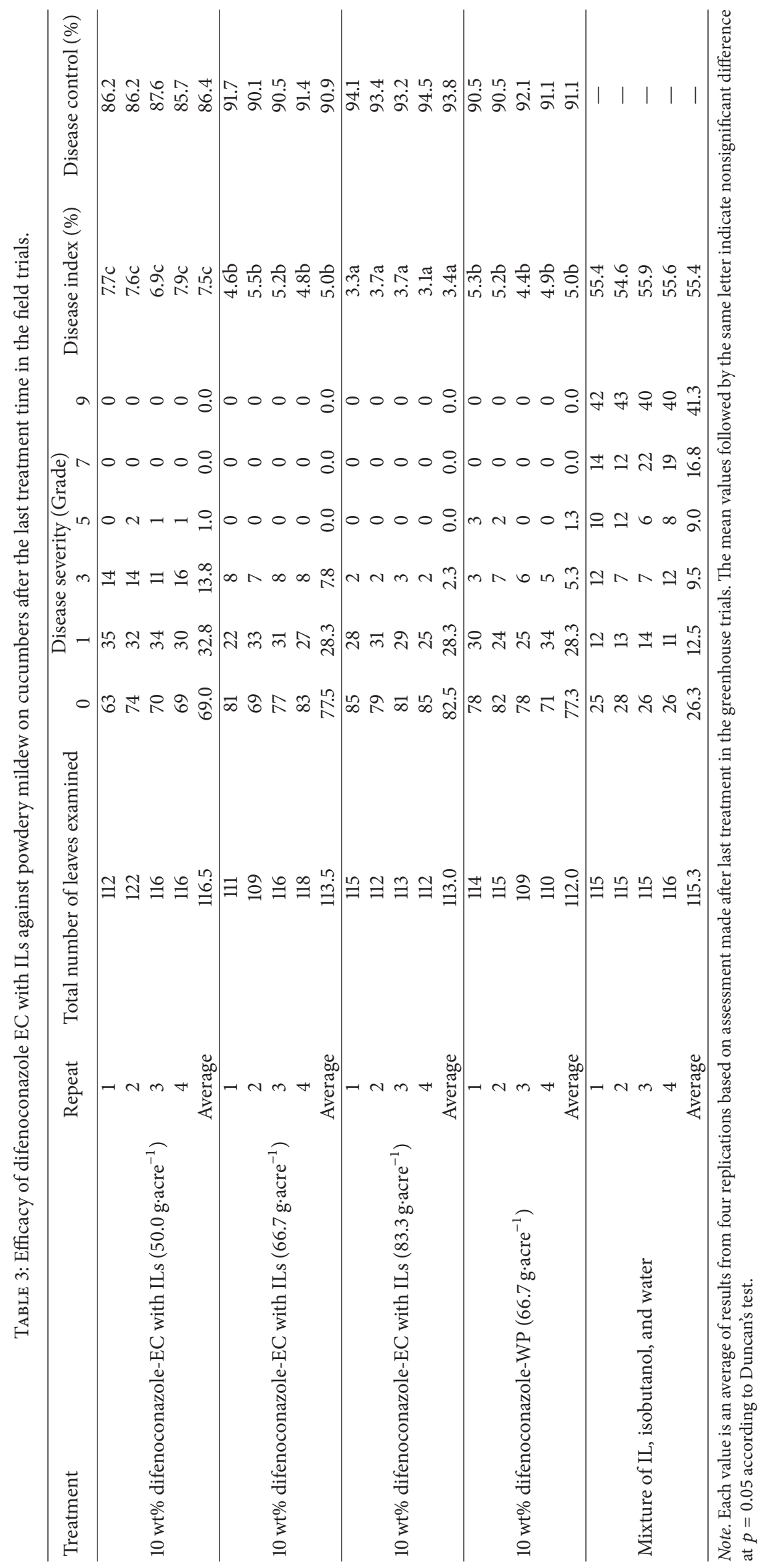


powdery mildew on cucumbers at a 0.05 level of significance. We recommend that the suitable dilution rate of $10 \mathrm{wt} \%$ difenoconazole EC with ILs against powdery mildew on cucumbers is from $50 \mathrm{~g} \cdot \mathrm{acre}^{-1}$ to $83.3 \mathrm{~g} \cdot \mathrm{acre}^{-1}$, which implies that the active ingredient of difenoconazole is from $5 \mathrm{~g} \cdot \mathrm{acre}^{-1}$ to $8.33 \mathrm{~g} \cdot$ acre $^{-1}$. Thus, an environment-friendly difenoconazole EC with ILs is obtained. The efficacy of this EC is similar to that of difenoconazole WP at the same dilution rate in the field trial.

\section{Conclusions}

Environment-friendly difenoconazole EC with ILs had stable physical properties through this study. IL 1- $n$-butyl-4-methylpyridinium bromide (5) is the most suitable alternative to the aromatic compounds of water-insoluble difenoconazole EC. The efficacy of $10 \mathrm{wt} \%$ difenoconazole EC with ILs is similar to that of $10 \mathrm{wt} \%$ difenoconazole WP. The use of nonflammable ILs reduces the risk to the environment while enabling cleaner and safer production, which prevents soil and groundwater pollution. However, more exploratory studies on the replacement of toxic organic solvents should be performed.

\section{Conflicts of Interest}

The authors declare that they have no conflicts of interest.

\section{Acknowledgments}

The authors gratefully acknowledge the Natural Science Foundation of China (no. 31201539).

\section{References}

[1] A. Garibaldi, D. Bertetti, S. Frati, and M. L. Gullino, "First report of powdery mildew caused by Golovinomyces cichoracearum on orange coneflower (Rudbeckia fulgida) in Italy," Plant Disease, vol. 92, no. 6, p. 975, 2008.

[2] Y. Elad, N. E. Malathrakis, and A. J. Dik, "Biological control of Botrytis-incited diseases and powdery mildews in greenhouse crops," Crop Protection, vol. 15, no. 3, pp. 229-240, 1996.

[3] X. Yang, X. Ma, L. Yang, D. Yu, Y. Qian, and H. Ni, “Efficacy of Rheum officinale liquid formulation on cucumber powdery mildew," Crop Protection, vol. 28, no. 12, pp. 1031-1035, 2009.

[4] V. Candido, G. Campanelli, G. Viggiani, L. Lazzeri, V. Ferrari, and I. Camele, "Melon yield response to the control of powdery mildew by environmentally friendly substances," Scientia Horticulturae, vol. 166, pp. 70-77, 2014.

[5] J. J. Kim, M. S. Goettel, and D. R. Gillespie, "Evaluation of Lecanicillium longisporum, Vertalec ${ }^{\circledR}$ against the cotton aphid, Aphis gossypii, and cucumber powdery mildew, Sphaerotheca fuliginea in a greenhouse environment," Crop Protection, vol. 29, no. 6, pp. 540-544, 2010.

[6] Z. H. Wang, T. Yang, D. M. Qin, Y. Gong, and Y. Ji, "Determination and dynamics of difenoconazole residues in Chinese cabbage and soil," Chinese Chemical Letters, vol. 19, no. 8, pp. 969-972, 2008.
[7] G. P. Munkvold, "Seed pathology progress in academia and industry," Annual Review of Phytopathology, vol. 47, pp. 285-311, 2009.

[8] M. Reuveni and D. Sheglov, "Effects of azoxystrobin, difenoconazole, polyoxin B (polar) and trifloxystrobin on germination and growth of Alternaria alternata and decay in red delicious apple fruit," Crop Protection, vol. 21, no. 10, pp. 951-955, 2002.

[9] M. S. Hamada, Y. Yin, and Z. Ma, "Sensitivity to iprodione, difenoconazole and fludioxonil of Rhizoctonia cerealis isolates collected from wheat in China," Crop Protection, vol. 30, no. 8, pp. 1028-1033, 2011.

[10] G. M. S. ElShafei, M. M. El-Said, H. A. E. Attia, and T. G. M. Mohammed, "Environmentally friendly pesticides: Essential oil-based w/o/w multiple emulsions for anti-fungal formulations," Industrial Crops and Products, vol. 31, no. 1, pp. 99-106, 2010.

[11] T. Welton, "Room-temperature ionic liquids: solvents for synthesis and catalysis," Chemical Reviews, vol. 99, no. 8, pp. 20712083, 1999.

[12] C. D. Tran, S. Challa, and M. Franko, "Ionic liquids as an attractive alternative solvent for thermal lens measurements," Analytical Chemistry, vol. 77, no. 22, pp. 7442-7447, 2005.

[13] A. Abdulkhani, E. Hojati Marvast, A. Ashori, and A. N. Karimi, "Effects of dissolution of some lignocellulosic materials with ionic liquids as green solvents on mechanical and physical properties of composite films," Carbohydrate Polymers, vol. 95, no. 1, pp. 57-63, 2013.

[14] J. P. Hallett and T. Welton, "Room-temperature ionic liquids: Solvents for synthesis and catalysis. 2," Chemical Reviews, vol. 111, no. 5, pp. 3508-3576, 2011.

[15] S. Keskin, D. Kayrak-Talay, U. Akman, and Ö. Hortaçsu, "A review of ionic liquids towards supercritical fluid applications," Journal of Supercritical Fluids, vol. 43, no. 1, pp. 150-180, 2007.

[16] Q. Yang and D. D. Dionysios, "Photolytic degradation of chlorinated phenols in room temperature ionic liquids," Journal of Photochemistry and Photobiology A: Chemistry, vol. 165, no. 13, pp. 229-240, 2004.

[17] J. L. Anderson and D. W. Armstrong, "High-stability ionic liquids. a new class of stationary phases for gas chromatography," Analytical Chemistry, vol. 75, no. 18, pp. 4851-4858, 2003.

[18] J. Dupont, R. F. de Souza, and P. A. Z. Suarez, "Ionic liquid (molten salt) phase organometallic catalysis," Chemical Reviews, vol. 102, no. 10, pp. 3667-3692, 2002.

[19] A. Mele, C. D. Tran, and S. H. De Paoli Lacerda, "The structure of a room-temperature ionic liquid with and without trace amounts of water: The role of $\mathrm{C}-\mathrm{H} \cdots \mathrm{O}$ and $\mathrm{C}-\mathrm{H} \cdots \mathrm{F}$ interactions in 1-n-butyl-3-methylimidazolium tetrafluoroborate," Angewandte Chemie - International Edition, vol. 42, no. 36, pp. 4364-4366, 2003.

[20] S. M. Mwongela, A. Numan, N. L. Gill, R. A. Agbaria, and I. M. Warner, "Separation of Achiral and Chiral Analytes Using Polymeric Surfactants with Ionic Liquids as Modifiers in Micellar Electrokinetic Chromatography," Analytical Chemistry, vol. 75, no. 22, pp. 6089-6096, 2003.

[21] Y. Zhao, J. Zhao, Y. Huang, Q. Zhou, X. Zhang, and S. Zhang, "Toxicity of ionic liquids: Database and prediction via quantitative structure-activity relationship method," Journal of Hazardous Materials, vol. 278, pp. 320-329, 2014.

[22] Z. Y. Zhang, G. H. Dai, Y. Y. Zhuge, and Y. B. Li, "Protective effect of Robinia pseudoacacia Linnl extracts against cucumber powdery mildew fungus, Sphaerotheca fuliginea," Crop Protection, vol. 27, no. 6, pp. 920-925, 2008. 
[23] F. J. Hills, L. Chiarappa, and S. Geng, "Powdery Mildew of Sugar Beet: Disease and Crop Loss Assessment," Phytopathology, vol. 70, no. 7, p. 680, 1980.

[24] P. Jungwirth and D. J. Tobias, "Ions at the air/water interface," Journal of Physical Chemistry B, vol. 106, no. 25, pp. 6361-6373, 2002.

[25] T. Fan, X. Wu, and Q. Peng, "Sparingly soluble pesticide dissolved in ionic liquid aqueous," Journal of Physical Chemistry B, vol. 118, no. 39, pp. 11546-11551, 2014. 


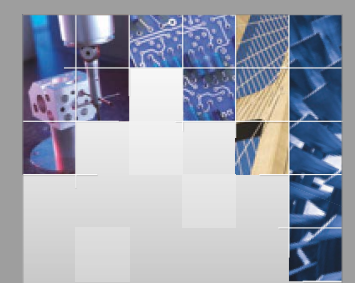

\section{Enfincering}
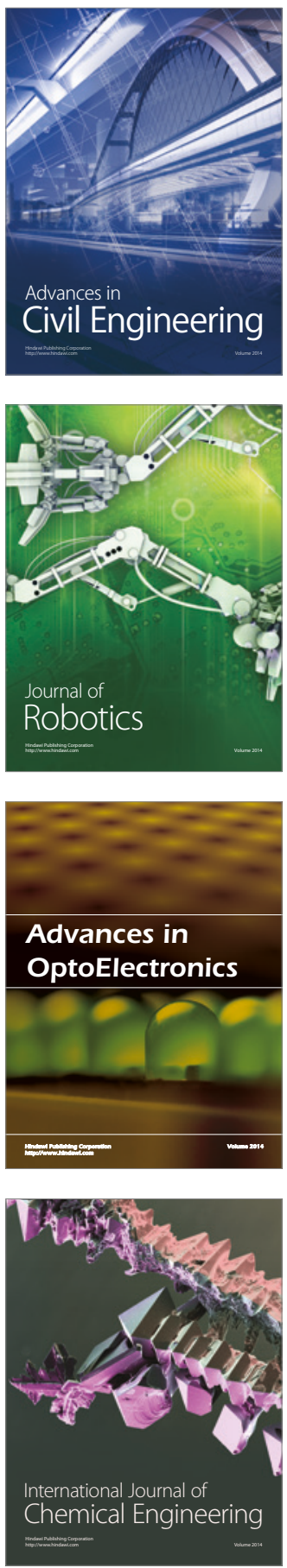

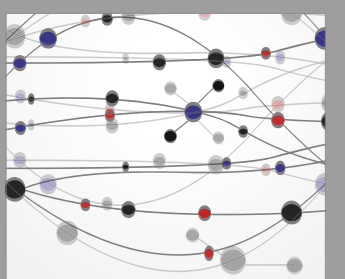

The Scientific World Journal

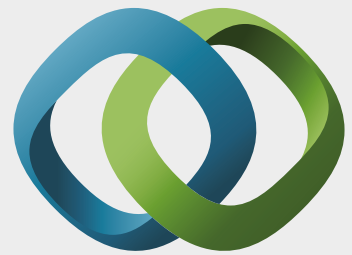

\section{Hindawi}

Submit your manuscripts at

https://www.hindawi.com
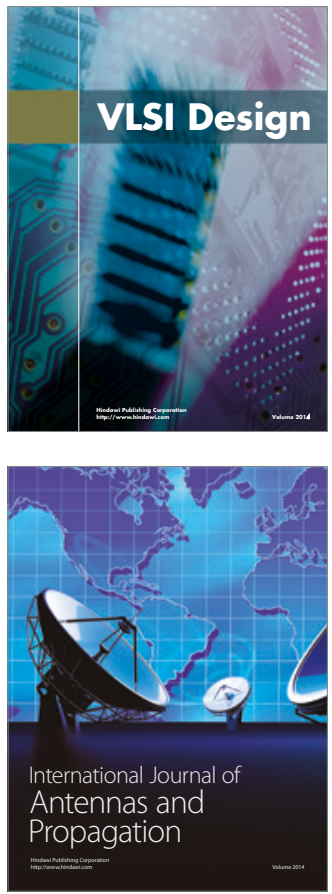

\section{Rotating}

Machinery
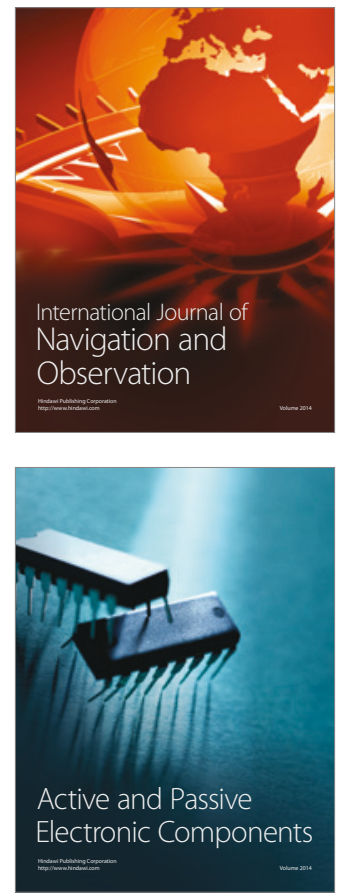
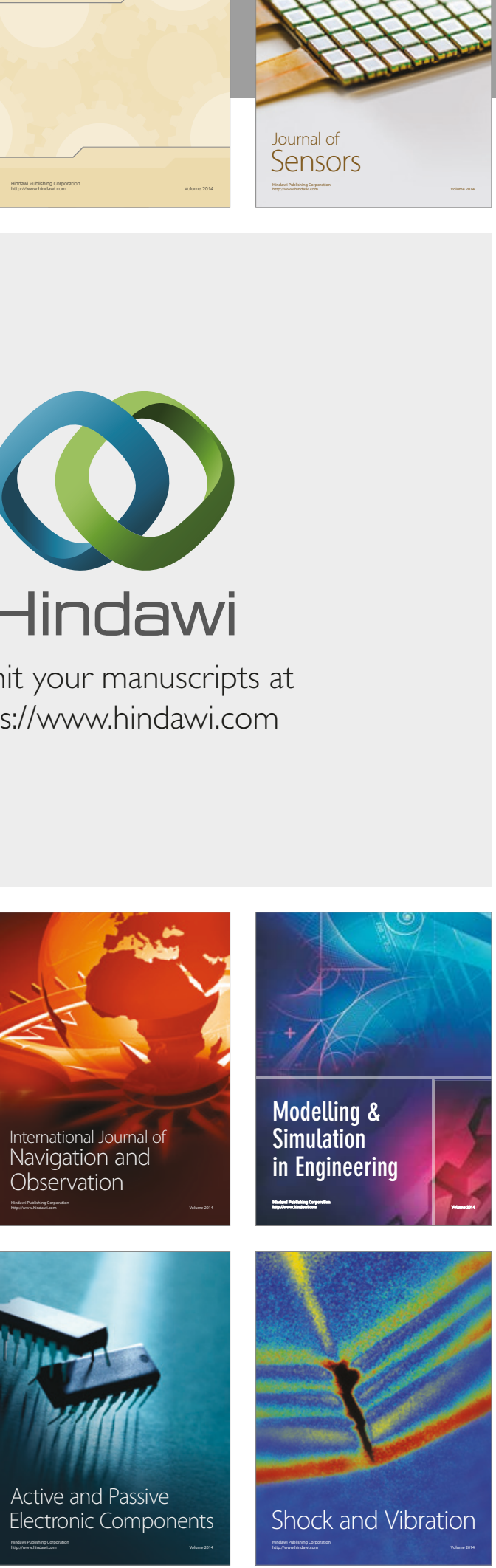
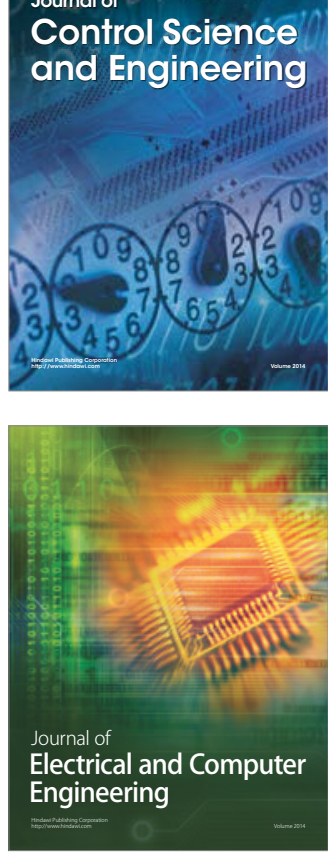

Distributed

Journal of

Control Science

and Engineering
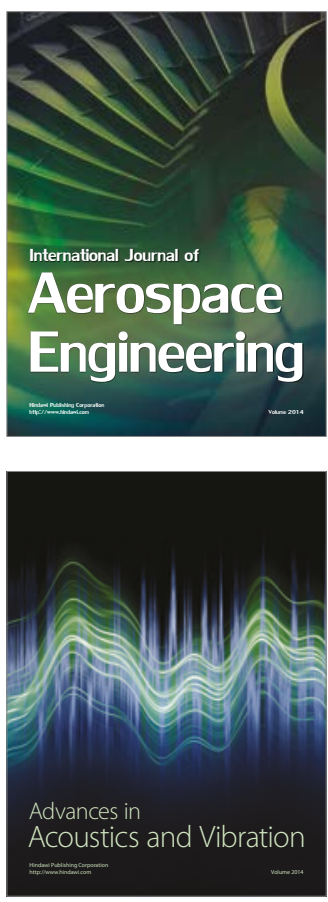

Sensor Networks 